\title{
Use of Social Media in Teaching-Learning Process in Internship Programme: Perspective of Secondary Level Pre- service Teachers
}

\author{
Pratyusha Ranjan Sahoo ${ }^{1^{*}}$ and Suraj Prakash Rautaray ${ }^{2}$ \\ ${ }^{1}$ Research Scholar, Regional Institute of Education, Bhubaneswar, Odisha, India \\ ${ }^{2}$ Assistant Professor, Rejendra University, Balangir, Odisha, India \\ *Corresponding author: sahoopratyusha93@gmail.com
}

Received: 24-05-2021

Revised: 19-07-2021

Accepted: 01-08-2021

\begin{abstract}
Social network is an online community that brings people with common interests, activities, experience. It is a forum for sharing news, photos, videos and events. It provides information about people and their social links. Elison (2007) defined social network sites as public web-based services that allow users to develop a personal profile, identify other users with whom they have a connection, read and react to posting made by other users on the site, and send or receive messages either privately or publicly. With the change in time, there has been a paradigm shift in the field of technology. Technology has become the substantial medium of interaction in the social world today. In the last few years, the web has evolved from a unidirectional information transfer tool to a bidirectional information sharing, interactive and participatory centre. The development of Web 2.0 leads to the emergence and proliferation of social media. Increased broadband availability, improvements of software tools and development of more powerful computers and mobile devices have been the important factors for the rapid growth of social media. In the present time, social media influences how we live, how we work, and now more than ever, how we learn. The present study has explored the use of social media in teaching and learning process during school internship programme. For the present study qualitative research approach was followed to collect data by using a self-constructed interview schedule. In this study, face-to-face mode of interview between the researcher and the sample or participants was employed. Population for the study is two years B.Ed. final year students of RIE, Bhubaneswar, from which 24 students were purposively selected as sample for the study. The participants comprised of 12 students from B.Ed. science and 12 students from B.Ed. arts, from which six were male and six were females in both cases. It was found that, almost all the participant answered about Facebook, Whatsapp, Twitter, YouTube, Instagram, Google Scholar, We Chat, Line, Skype, Wikipedia, Blogs, LinkedIn, Google plus and Flickr. Participants used YouTube, Wikipedia, Blogs, Google plus, Google Scholar for teaching and learning processes. Social media enhanced the teaching learning process up to a great extent like receiving and sending information, using as an engagement tool, improving collaboration with peers, teachers and improving linkage with outside world as revealed from their views. Social media helps in providing a better learning environment and platform to students to learn more easily in better and smoother way. The paper lists educational implications based upon findings.
\end{abstract}

Keywords: Social network, social media, teaching- learning, web 2.0

In this era of $21^{\text {st }}$ century, technology has taken a stance in helping the human community for a substantial medium of interaction in the social world. It helps to connect with people anywhere in
How to cite this article: Sahoo, P.R. and Rautaray, S.P. (2021). Use of Social Media in Teaching-Learning Process in Internship Programme: Perspective of Secondary Level Pre-service Teachers. Educational Quest: An Int. J. Edu. Appl. Soc. Sci., 12(2): 147-152.

Source of Support: None; Conflict of Interest: None 
the world in no time. Over these years the world has explored many exciting opportunities with new technologies which have changed the trends and have brought people more closely with each other. Technology has changed the way people interact and has brought about the emergence of an open social platform such as social media that allows the inhabitants of this planet earth to connect with each other making the world a global village.

In the last few years, the web has evolved from a unidirectional information transfer tool to a bidirectional information sharing, interactive and participatory centre. This new conception of the Web as a platform for computing and collaborative interaction has been supported by the development of Web 2.0 technologies and standards. The result has been the fast proliferation of social media. The latter basically refers to a category of web-based tools and platforms that facilitates discussion, participation, and sharing of various forms of content (namely, text, video, audio and image) in a very convenient way. Andreas Kaplan and Michael Haenlein define social media as "a group of Internet-based applications that build on the ideological and technological foundations of Web 2.0 and that allow the creation and exchange of user-generated content.

Increased broadband availability, improvements of software tools and development of more powerful computers and mobile devices have been the important factors for the rapid growth of social media. With the use of social media interfacing through computer and mobile devices becoming more prevalent, user interaction from the platform to face to face engagement is being promoted (Teclehaimanot \& Hickman, 2011). This free flow of information is enhanced through new communication tools and sites that are referred to as social networking sites. The phrase "social networking sites" is an umbrella term used for social media, but is not limited to Whatsapp, Facebook, Twitter, LinkedIn, and Myspace. Social Media is internet based technologies that allow more free flowing communication among its users. Social Networking is "the act of engagement," while social media is the tool used to communicate with mass audience (Hartshorn, 2010). It has reformed the process of connecting people and interacting with them to make the things done with ease.
New communication tools enhance this communication through audio and visual capturing string, connecting and retrieving features that include, Blogs that make authors publish/post their work and invite comments on it, Wikis which have capability to promote and facilitate "common creation" through joining academic ventures, Social book marking is used to enable users for collating, tagging, and sharing websites of their interests, Media sharing spaces provide spaces and opportunities to the user community of posting and sharing pictures, podcasts and videos, Collaborative tools extend documents' sharing and editing capabilities to multiple users, Social networking sites have abilities of promoting virtual communities to interact and communicate synchronously or asynchronously (Fogel \& Nehmad, 2009).

It's no secret that social media is in the middle of most people's lives. Social media influences how we live, how we work, and now more than ever, how we learn.

\section{RESEARCH QUESTIONS}

Taking into the consideration of the background of the study, the researcher accentuated the following research questions:

(i) Do social media has any use in teaching and learning process?

(ii) Do the pre service teachers' posses' knowledge of using different kinds of social media platforms in their classrooms?

(iii) How the use of social media has been managed effectively in the classrooms?

(iv) Does social media promote educational opportunities for improving students' understanding?

\section{OBJECTIVE}

Social media has been a great platform for the pre service teachers which can help them to grow and improve their competencies in the teaching learning process. The study has been performed with the intention to explore the use of social media in teaching and learning process during school internship programme. 


\section{METHODOLOGY}

\section{(i) Research Design}

For the present study qualitative research approach was followed to collect data by using a selfconstructed interview schedule. Quantitative research methodology was not employed rather than qualitative research methodology was used, as it is better and appropriate to collect data in the natural settings than a contrived situation (Creswell, 2007). Therefore, the researchers in this study was able to find out detailed information about the use of social media in the teaching learning process.

\section{(ii) Population}

The targeted population for the study is two years B.Ed. final year students of RIE Bhubaneswar who have just completed their internship activities in different Jawahar Navodaya Vidyalayas.

\section{(iii) Sample and sampling procedure}

24 students were purposively selected as participants for the study. The participants were from two year B.Ed. course of Regional Institute of Education, Bhubaneswar. They all have successfully completed four months of internship in different assigned Jawahar Navodaya Vidyalayas for the partial fulfilment of the course. The sample comprised of 12 students from B.Ed. science and 12 students from B.Ed. arts, from which six were male and six were females in both cases (Table 1).

Table 1: Participants

\begin{tabular}{lccc}
\hline \multicolumn{2}{c}{ Science (12) } & \multicolumn{2}{c}{ Arts (12) } \\
\hline Male & Female & Male & Female \\
\hline 06 & 06 & 06 & 06 \\
\hline
\end{tabular}

\section{(iv) Data collection procedure}

The period for data collection was lasted for almost a month. In this study, face-to-face mode of interview between the researcher and the participants were employed to collect detailed information about their experiences about the use of social media in the classroom settings. The whole process of interview was recorded by using an audio recorder for precise transcription and researcher noted the valuable and important points delivered by the participants.

\section{(v) Data Analysis}

The data collected by both recorded and written forms were transcribed and categorized based on the answers of the participants to each questions. The answers were then categorized to themes and sub themes.

\section{RESULTS AND FINDINGS}

This chapter presents the results of the data to answer the research questions and appropriated.

Themes and subthemes were emerged related to each research question. The data collected from this research study are discussed under the following headings.

\section{(a) Social media sites Pre-service teachers' generally use and conversant}

Almost all the participant answered about Facebook, Whatsapp, Twitter, YouTube, Instagram, Google Scholar, We Chat, Line, Skype, Wikipedia, Blogs, LinkedIn, Google plus and Flickr. Different social media sites Pre-service teachers' used during internship were listed below (Table 2).

Table 2: Social media sites used and conversant by the participants

\begin{tabular}{ll}
\hline Social media sites & Numbers of participants \\
\hline Facebook & 24 \\
Whatsapp & 24 \\
Twitter & 16 \\
YouTube & 24 \\
Instagram & 21 \\
Google Scholar & 24 \\
We Chat & 8 \\
Line & 6 \\
Skype & 9 \\
Wikipedia & 24 \\
Blogs & 13 \\
LinkedIn & 7 \\
Google plus & 24 \\
Flickr & 3 \\
\hline
\end{tabular}

The above table gives the idea about the different sites the participants used during the internship period.

(b) Social media sites visited and generally used by the Pre-service teachers during taking the classes in internship.

Participants used YouTube, Wikipedia, Blogs, Google plus, Google Scholar for teaching and 
learning processes. Participants had shown related videos during the classes in Samsung lab and computer labs.

Participants 5, 7, 10,11, 12,17,19,20 and 23 had used Google Scholar to share the information related to their topics and they stated that students were also given task and they had complete the tasks and whenever they are in computer laboratory they have to send the tasks to group.

All the participants had used Wikipedia to search for different information and help students to guide better.

Participants 2, 4, 6, 14, 15 used the Blogs and they had also taught the students how to create blogs and make use of Blogging facilities.

When asked about other sites, participant 1 answered that, In JNVs there is no provision for students to keep mobile phones and use of Facebook, Whatsapp and other social media applications like We Chat, Skype, Instagram etc. are strictly restricted and prohibited". Other participants also agreed on the same point.

Participant 3, 23 and 24 used Skype to help students to interact with outside Resource Person.

All the participants were with the view that YouTube had helped them to understand and learn them complex concepts and then helped during taking classes as practical demonstrations were demonstrated thoroughly in the video lectures, these are great source of learning materials and the practical which could not be shown due to unavailability of resources were being able to demonstrated with the help of YouTube videos.

Participant 22 stated that it makes teaching and learning more interesting and attractive.

Participant 11 stated, I use LinkedIn basically for connections; I connect with people who share the same interest in terms of educations.

\section{(c) Role of social media in enhancing the teaching learning process during internship period}

Social media has a great impact on the teaching learning process as it helps in the following processes. The results revealed from participants are presented below:

(i) Receiving and sending materials and information: All the participants responded that social media is a very good platform for receiving and sending information or materials to students and their friends.

It became easy, time consuming and cost effective to help each other during the internship period. Participant 10 told that knowledge sharing among their friends help them to grow professionally as well as it improves the bonding between them. People who are better in something or the other share their ideas, viewpoints and approach to a particular problem which help others to follow in their classroom settings as well.

(ii) As an information centre: The Social Media changes the way of study in current generation. The students are now referring the Social Media to get the information. There is some doubts in the authenticity of the information which is available on the internet even it is the best medium to get the information and also time saving. Social media like Wikipedia, Blogs, and YouTube are used as digital library. Any information you need can get in no time. Many study materials and innovative teaching videos have been uploaded in the webs mainly YouTube helps to address and clarify the doubts of the students and it also helps students to visualise complex concepts easily.

(iii) Increasing the participation and collaboration: Social media platforms like Google Scholar helps teachers to discuss the assignments. Students had been given tasks to perform and instructed them to send the assignments to the group and discussions were being carried out. It made the things possible for an online discussion in which students, teachers and other resource persons can take part. It also fosters collaboration which means working together jointly, intellectually and socially to achieve a common goal. Prince (2004) claimed that the core elements of collaborative learning is that emphasis is on student's interactions rather than on learning as a solitary activity.

(iv) Linkage to outside world: It also makes a connection with the outside world. It makes things possible to interact with the persons who are far away. It helps to take a tour of the whole world within no time.

(v) Increasing students' engagement: Social media tools are effective ways to increase the students' engagement. It increases the participation of students. It helps students to actively engage in co- 
constructing their learning experiences with teachers and may feel comfortable to express themselves. Using Google applications enable students to have access to valuable learning resources regardless of time and place.

\section{DISCUSSIONS OF RESULT}

The present study demonstrates how pre service teachers are familiar with use of social media in the classrooms for teaching and learning. Based on the findings it was realized that people are conversant as well as familiar with social media. In general the pre service teachers used social media as a platform for exploring information, sharing the materials, discussing the assignments etc. Boateng (2016) in his study also agreed and stated about the above use of social media in teaching and learning. It was also realized that it allows people to get connected with each other, interact to each other, access endless or unlimited resources. Taylor et al. (2012) in their study had found that it has a significant effect on the learning as it makes teaching and learning more interesting. Faizi (2013) in his study described the benefits of using social media. Looking at the responses from the participants, it can also be validated that, pre service teachers are very much familiar with the use of different social networking sites and its significant uses in teaching and learning. Social media can therefore be associated with an increased tendency for young people to multitask, to rely on a digital juggling of daily activities and commitments (Subrahmanyam and Smahel, 2011).

\section{CONCLUSION}

This present study focused on the use of social media by pre service teachers during the internship period. After going through all the discussions, it can be concluded that, pre service teachers are well versed with the use of social media in their classrooms for teaching and learning. The data revealed that the participants are in favour of using the social media in classrooms which can improves the teaching learning processes and learning achievement of the students. It also can make learning more interesting. It can be a substitute to different learning resources in case of unavailability. So it can be inferred from the study that the two years B.Ed. final year students of Regional Institute of Education, Bhubaneswar are familiar and conversant with the use of different kinds of social media which can be used during teaching and learning to improve learning conditions more attractive and better.

\section{EDUCATIONAL IMPLICATIONS}

Understanding of social media, social networking sites, its uses in teaching learning would be of great relevance to students, teachers, researchers, policy formulators and practitioners. It has lot many educational implications which are listed below:

(i) It may help policy formulators to rethink, plan, strategies, and reconstruct the attitudes of using social media in present context.

(ii) It will be helpful teacher educators to plan and share useful strategies which can be useful for Pre-service teachers.

(iii) Teachers may be find it suitable to use it in teaching learning process as it may make understanding better and clear. It may help them to use as a constructive way of learning as it uses the collaborative approach in learning.

(iv) Researchers may think of different researches related to practices, use, impact, its effectiveness, barriers etc. in teaching and learning process.

(v) It can help parents to understand that social media may be used for a better career opportunities.

(vi) The study can help principals, head teachers to take certain steps to motivate teachers to use different social media sites to enhance teaching learning activities and must provide ample opportunities to students for using some authentic sources to better their understandings.

\section{REFERENCES}

Boateng, R.O. and Amankwaa, A. 2016. The Impact of Social Media on Student Academic Life in Higher Education. Global Journal of Human-Social Science; G Linguistics EEducation, 16(4).

Creswell, J.W. 2007. Qualitative enquiry and research design: Choosing among five approaches.

Ellison, N.B. 2007. Social network sites: Definition, history, and scholarship. Journal of Computer-Mediated Communication, 13(1): 210-230. 
Faizi, R., Afia, A.E. and Chiheb, R. 2013. Exploring the Potential Benefits of Using Social media in Education. International Journal of Environmental Protection, 3(4).

Fogel, J. and Nehmad, E. 2009. Internet social network communities: Risk taking, trust and privacy concerns. Computers in Human Behavior, 25(1): 153-160.

Hartshorn, S. 2010. 5 Differences between Social Media and Social Networking. Social Media Today.

Kaplan Andreas M. and Haenlein Michael. 2010. “Users of the world, unite! The challenges and opportunities of social media". Business Horizons, 53(1): 61.

Prince, M. 2004. "Does active learning work? A review of the research". Journal of Engineering Education, 93: 223-231.

http://dx.doi.org/10.1002/j.2168-9830.2004.tb00809.x
Rajesh, S. and Michael, J. 2015. Effectiveness of Social Media in Education. International Journal of Innovative Research in Advanced Engineering, 10(2).

Social Media for Teaching and Learning, Annual Survey of Social Media use by higher education faculty, 2013.

Subrahmanyam, K. and Šmahel, D. 2011. Adolescents' Digital Worlds: An Introduction. In Digital Youth. (pp. 1-25). Springer New York.

Taylor, R., King, F. and Nelson, G. 2012. Students Learning Through Social Media. Journal of Sociological Research, 3(2).

Teclehaimanot, B. and Hickman, T. 2011. Student-teacher interaction of Facebook: What students find appropriate. TechTrends, 55(3): 19-30. 